\title{
Noninvasive ventilation for acute respiratory failure in children - a systematic review
}

\author{
Ventilação não invasiva em crianças com insuficiência respiratória aguda - \\ uma revisão sistemática
}

\author{
Carolina Silva Gonzaga ${ }^{1}$, Dafne Cardoso Bourguignon da Silva² ${ }^{2}$, Carolina Figueira Rabello Alonso ${ }^{3}$, \\ Carlos Augusto Cardim de Oliveira ${ }^{4}$, Lara de Araújo Torreão ${ }^{5}$, Eduardo Juan Troster ${ }^{6}$
}

\begin{abstract}
Objective: To assess the role of noninvasive ventilation in the treatment of children with acute respiratory failure. Methods: A systematic review of literature on noninvasive ventilation in MEDLINE, LILACS, EMBASE, and Cochrane databases, besides references in articles. The outcomes evaluated were responses in blood oxygenation and ventilation, and patient survival. Results: A total of 120 studies on noninvasive ventilation were found as of May, 2010. Of these, only 19 were about noninvasive ventilation in children. On the other hand, there are prospective and cohort clinical trials leading to a level II quality of evidence concerning the use of noninvasive ventilation in children. Conclusion: There is scientific evidence for proposing the use of noninvasive ventilation, with a B-II degree of recommendation.
\end{abstract}

Keywords: Pulmonar ventilation; Anoxia; Hypercapnia; Respiratory insufficiency; Child

\section{RESUMO}

Objetivo: Avaliar o papel da ventilação não invasiva no tratamento de crianças com insuficiência respiratória aguda. Métodos: Revisão sistemática da literatura sobre ventilação não invasiva nas bases MEDLINE, LILACS, EMBASE e Cochrane, além de referências de artigos. Os desfechos avaliados foram resposta sobre a oxigenação e ventilação sanguínea, e a sobrevida dos pacientes. Resultados: Foram encontrados 120 estudos sobre ventilação não invasiva até Maio de 2010. Destes, apenas 19 eram sobre ventilação não invasiva em crianças. Já há ensaios clínicos prospectivos e de coorte, levando a uma qualidade de evidência nível II sobre 0 uso de ventilação não invasiva em crianças. Conclusão: Já há evidência científica para recomendar o uso da ventilação não invasiva, com um grau de recomendação B-Il.

Descritores: Ventilação pulmonar; Anóxia; Hipercapnia; Insuficiência respiratória; Criança

\section{INTRODUCTION}

Among the diseases that place at risk the life of a pediatric patient, and especially, its future quality of life, acute respiratory failure (ARF) is one of the most important. A child's respiratory system has several particularities that facilitate the development of respiratory insufficiency. In addition, respiratory diseases occur frequently in the pediatric age range.

The use of invasive mechanical ventilation allows a more adequate treatment of patients with ARF; but positive pressure in the patients' airways acts inversely to normal respiratory physiology. This may result in complications due to lack of pressure. Additionally, the intubation procedure and the presence of the cannula in the airway may promote local lesions and predispose to pulmonary infections.

As an alternative to tracheal intubation, noninvasive ventilation (NIV) is a technique in which positive pressure is applied to the patient's airway by means of masks or interfaces without tracheal cannulation.

\footnotetext{
Study carried out at Instituto da Criança Professor Pedro de Alcântara, Universidade de São Paulo - USP, Sao Paulo (SP), Brazil.

${ }^{1}$ Physical therapist; Hospital Aliança de Salvador, Bahia (BA), Brazil.

${ }^{2}$ Intensive Care Unit, Instituto de Oncologia Pediátrica, Escola Paulista de Medicina, Universidade Federal de São Paulo - UNIFESP, Sao Paulo (SP), Brazil.

${ }^{3}$ Instituto de Oncologia Pediátrica, Escola Paulista de Medicina, Universidade Federal de São Paulo - UNIFESP, Sao Paulo (SP), Brazil.

${ }^{4}$ Universidade da Região de Joinville - UNIVILLE, Joinville (SC), Brazil.

${ }^{5}$ Universidade Federal da Bahia - UFBA, Salvador (BA), Brazil.

${ }^{6}$ Pediatric Intensive Care Unit, Hospital Israelita Albert Einstein - HIAE, Sao Paulo (SP), Brazil.

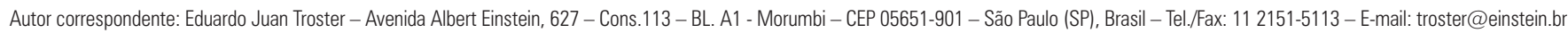
Received: Jun 12, 2010 - Accepted: Feb 15, 2011

There is no conflict of interest.
} 
The use of NIV in selected groups of adult patients, such as those with acute exacerbation of chronic obstructive pulmonary disease (COPD), reduces the need for intubation, mortality, and costs of treatment ${ }^{(1)}$.

In 1987, the first use of NIV with a nasal mask was recorded in a six-year-old child with a primary diagnosis of alveolar hyperventilation ${ }^{(2)}$. Over the last 20 years, the number of experiences with the use of NIV in children has been increasing.

\section{OBJECTIVE}

To discuss the accumulated experience on NIV in clinical trials with the purpose of evaluating its role in the treatment of ARF in pediatric patients.

\section{METHODS}

\section{Identification of studies}

The bibliographical survey was made systematically, seeking publications in Portuguese, English, and Spanish. The following databases were used, from the onset to May, 2010: MEDLINE (as of 1966); LILACS (as of 1983); EMBASE (as of 1974); Cochrane Library (as of 1993). Also used were the references cited in reviews and articles.

The terms used for the investigation were "noninvasive ventilation;" "acute respiratory failure;" "BIPAP;" "CPAP;" "hypoxemia;" "hypercapnia."

\section{Selection criteria}

The following criteria were considered for study selection:
A. Study design
- Randomized clinical trials.
- Case series.
- Systematic reviews.
B. Population
Children and adolescents up to 18 years of age with ARF.
C. Exclusion criteria

- Articles published in languages other than Portuguese, English, or Spanish.

- Articles that covered the use of NIV in chronic patients and in those with obstructive sleep apnea syndrome.

- Studies that covered the use of NIV in newborns and terminal patients.

D. Type of intervention

Utilization of NIV by means of masks, with comparative analysis (pre- and post-NIV in the same individual, or with controls submitted to conventional treatment).

E. Types of outcomes evaluated

- Primary outcomes

1. Need for intubation.

2. Survival.

- Secondary outcomes

1. Effects on heart rate and breathing rate.

2. Effects on oxygenation and ventilation (alteration of arterial oxygen pressure $\left(\mathrm{PaO}_{2}\right)$, arterial carbon dioxide pressure $\left(\mathrm{PaCO}_{2}\right)$, and oxygen saturation).

F. Classification of the level of scientific evidence

The GRADE System was used, recognized by the foremost societies and specialties and by the Public Health Service of the United States, as per Table $1^{(3)}$.

\section{RESULTS}

\section{Systemic search in publications}

One hundred and twenty studies on NIV were found during the study period. Of these, only 19 satisfied the established selection criteria, and they are shown on Chart 1.

In a systematic review of NIV with negative pressure, only one study, in which 33 children with bronchiolitis were studied, was considered eligible. The experimental group treated with negative pressure NIV displayed a reduced need for oxygen in one hour and none of the children in this group required CPAP or invasive mechanical ventilation. The authors concluded that there was information lacking and that controlled

Table 1. Score system of recommendations, according to the Public Health Service of the United States

\begin{tabular}{ll}
\hline Stregth of recommendation & Quality of evidence \\
\hline A. Good evidence supporting recommendation for use & 1. Evidence of at least one appropriate randomized controlled trial, \\
B. Moderate evidence supporting the recommendation of use & $\begin{array}{l}\text { 2. Evidence of at least one well designed trial, not randomized; of cohort or case-control studies (preferably } \\
\text { from more than one center); of several temporal series or of significant results of non-controleed trials }\end{array}$ \\
$\begin{array}{ll}\text { C. Weal evidence supporting recommendation } & \text { 3. Evidence of experts in the subject, based on clinical experience, descriptive studies or reports of experts } \\
\text { D. Moderate evidence supporting against recommendation of use } & \\
\text { E. Good evidence supporting against recommendation of use } & \end{array}$
\end{tabular}

Source: Guyatt GH, Oxman AD, Vist GE, Kunz R, Falck-Ytter Y, Alonso-Coello P, Schünemann HJ; GRADE Working Group. GRADE: an emerging consensus on rating quality of evidence and strength of recommendations. BMJ. 2008;336(7650):924-6 (3) 
Chart 1. Studies about noninvasive ventilation in children with acute respiratory failure, 1993-2010

\begin{tabular}{|c|c|c|c|}
\hline Author & Study (n) & Year of publication & Population \\
\hline Akingbola et al. ${ }^{(4)}$ & Case report (2) & 1993 & Children with atelectasis \\
\hline Fortenberry et al. ${ }^{(5)}$ & Case series (28) & 1995 & Children with ARF \\
\hline Padman et al. ${ }^{(6)}$ & Case series (34) & 1998 & Patients aged between 6 months and 18 years with ARF \\
\hline Sprague et al. ${ }^{(7)}$ & Case series (5) & 2000 & $\begin{array}{l}\text { Patients aged between } 12 \text { years and } 18 \text { years with ARF secondary to } \\
\text { cystic fibrosis }\end{array}$ \\
\hline Akingbola et al. ${ }^{(8)}$ & Case report (3) & 2002 & Children with asthma and hypercapnia \\
\hline Shah et al. ${ }^{(9)}$ & Systematic review & 2003 & Children with bronchiolitis in ARF \\
\hline Thill et al. ${ }^{(10)}$ & Randomized crossover clinical trial (16) & 2004 & Children with lower airways obstruction \\
\hline Piastra et al. ${ }^{(11)}$ & Case series (4) & 2004 & $\begin{array}{l}\text { Children aged between } 9 \text { and } 17 \text { years with acute leukemia and } \\
\text { hypoxemic ARF }\end{array}$ \\
\hline Villanueva et al. ${ }^{(12)}$ & Case series (23) & 2005 & Hypoxemic and hypercapnic ARF or respiratory failure after extubation \\
\hline Chin et al. ${ }^{(13)}$ & Case series (15) & 2005 & $\begin{array}{l}\text { Children aged } 5 \text { months and } 14 \text { years, submitted to liver transplant, that } \\
\text { progressed with ARF and atelectasis }\end{array}$ \\
\hline Prado et al. ${ }^{(14)}$ & Case series (14) & 2005 & $\begin{array}{l}\text { Children aged between } 1 \text { month and } 13 \text { years, with ARF, reduced } \\
\text { oxygenation (saturation }<93 \% \text { with FiO2 }>40 \% \text { ) and ventilation }(\mathrm{pH}< \\
\text { 7,25), besides radiological impairment }\end{array}$ \\
\hline Carroll e Schramm ${ }^{(15)}$ & Case series (5) & 2006 & $\begin{array}{l}\text { Children aged between } 2 \text { years and } 18 \text { years, with acute asthma, } \\
\text { hypoxemia and increased respiratory work }\end{array}$ \\
\hline Essouri et al. ${ }^{(16)}$ & Retrospective cohort (114) & 2006 & Patients aged 15 to 17 years \\
\hline Yañez et al. ${ }^{(17)}$ & Prospective randomized clinical trial & 2008 & $\begin{array}{l}50 \text { patients with ARF, } 25 \text { received NIV and } 25 \text { received conventional } \\
\text { treatment with medication and } 02 \text { nebulization }\end{array}$ \\
\hline Essouri et al. ${ }^{(18)}$ & Prospective clinical trial & 2008 & $\begin{array}{l}\text { Patients aged } 1 \text { to } 18 \text { years, weighting more than } 10 \mathrm{~kg} \text {, admitted to } \\
\text { the ICU with ARF, moderate hypercapnia as defined by a respiratory } \\
\text { frequency equal or more than the } 97 \text { percentile for age associated to a } \\
\text { PCO2 } \geq 40 \mathrm{mmHg}\end{array}$ \\
\hline Pancera et al. ${ }^{(19)}$ & Retrospective study & 2008 & $\begin{array}{l}\text { Children amitted to the ICU of Hospital do Câncer between June } 1997 \\
\text { and May 2005. Two hundred thirty nine patients were included }\end{array}$ \\
\hline & & & And 120 of them received NIV as the first ventilation technique \\
\hline Ottonello et al. ${ }^{(20)}$ & Retrospective study & 2007 & $\begin{array}{l}\text { Twenty patients with mean ages of } 7.4 \text { years, with ARF, received NIV } \\
\text { and were divided into two groups for analysis: hypoxic and hypercapneic } \\
\text { group. }\end{array}$ \\
\hline Codazzi et al. ${ }^{(21)}$ & Case series (15) & 2006 & Fifteen children from 1 month to 5 years with hypoxemic ARF \\
\hline Piastra et al. ${ }^{(22)}$ & Viability study prospective cohort & 2009 & Twenty three immunocompromised patients with ARDS \\
\hline
\end{tabular}

ARF $=$ acute respiratory failure, ICU $=$ intensive care unit, NIV $=$ non invasive ventilation, ARDS = acute respiratory distress syndrome

studies would be necessary which could support the use of negative pressure NIV in children with ARF ${ }^{(9)}$.

The first crossover randomized clinical trial assessed the effects of NIV in 16 children with obstruction of the lower airways, characterized by increased breathing work and dyspnea, using the Clinical Asthma Score (CAS). Patients were randomized to two groups: Group 1, which received NIV in addition to conventional treatment (high flow oxygen, inhalation with bronchodilator, and corticoids) for two hours; and Group 2, which during the first two hours received only conventional treatment. After two hours, treatment between the groups was inverted (crossover): Group 1 began to receive only conventional treatment and Group 2 received NIV in addition to conventional treatment. There was significant improvement in respiratory rate $(\mathrm{p}<0.0001)$ and CAS $(\mathrm{p}<0.0001)$ in the NIV group ${ }^{(10)}$.

In the study by Villanueva, the effects of NIV were evaluated in 23 patients with hypoxemic respiratory insufficiency, hypercapnia, or postextubation respiratory insufficiency. After the start of NIV, there was significant improvement of the respiratory rate $(\mathrm{p}<0.001)$, heart rate $(\mathrm{p}=0.001)$, and of the $\mathrm{PaO} 2 / \mathrm{FiO} 2$ ratio $(\mathrm{p}=0.010)$. Of the 23 patients who received NIV, five required intubation and invasive mechanical ventilation ${ }^{(12)}$.

At a single center, 15 children aged one month to five years with hypoxemic respiratory insufficiency were evaluated. NIV was performed with additional sedation, when necessary, and the mask was well tolerated by all patients. Of the 15 children, 10 had multiple organ dysfunction and 9 were under one year of age. None of them experienced complications. Oxygenation improved after two hours of NIV, and no hemodynamic variation was detected ${ }^{(21)}$.

The efficacy of NIV was evaluated in an Italian Intensive Care Unit (ICU) with 24 beds, during two years, analyzing $\mathrm{pH}, \mathrm{CO} 2, \mathrm{SatO} 2$, respiratory rate, and need for oxygen. Twenty patients with a mean age of 7.4 years $( \pm 0.28$ years $)$, with ARF, received NIV, and for the analysis they were divided into two groups: 
hypoxic group and hypercapnic group. Of these 20 patients, 15 displayed an improvement in oxygenation and ventilation; five required invasive mechanical ventilation; and two experienced pressure ulcers on nasal bridges, which were rapidly reversible ${ }^{(20)}$.

Essouri et al. ${ }^{(16)}$ carried out a retrospective cohort study with patients aged 15 to 17 years treated with NIV for two hours or more, between January $1^{\text {st }}, 2000$, and December $31^{\text {st }}$, 2004. Included were 114 patients, and of these, $83(77 \%)$ were successfully treated with NIV, with no intubation. The success of NIV use was significantly lower $(22 \%)$ in the group with acute respiratory distress syndrome (ARDS). PRISM II and the Pediatric Logistic Organ Dysfunction (PELOD) at admission were clearly higher in patients who did not have success with NIV. In the group of responders to NIV, there was a distinct drop in respiratory rate and $\mathrm{PCO} 2$ within the first two hours of NIV. A multivariate analysis showed that the diagnosis of ARDS and the high value of PELOD were predictive factors for treatment failure with NIV.

Yañez et al. ${ }^{(17)}$ conducted a controlled randomized prospective multicentric study in Santiago, Chile. Fifty patients with ARF were studied; 25 received NIV and 25 received conventional treatment with medication, inhalation, and $\mathrm{O} 2$ nebulization. Comparing the values to those of admission, the $\mathrm{PaO} 2 / \mathrm{FiO} 2$ ratio and cardiac and breathing rates after our hour of treatment improved significantly in the group that received NIV. The improvement continued to be observed over time, with a drop in heart rate after six hours of therapy. Use of intubation was $28 \%$ lower in the group that received NIV relative to controls.

Essouri et al. ${ }^{(18)}$ published a second study in 2008, which was prospective, carried out from December 2004 to January 2007. Patients from one to 18 years of age were evaluated who weighed more than 10 $\mathrm{kg}$, admitted to the ICU with moderate hypercapnic respiratory insufficiency (defined by respiratory rate equal to or greater than the $97^{\text {th }}$ percentile for the age group, associated with $\mathrm{PCO} 2 \geq 40 \mathrm{mmHg}$ ). Only patients treated with NIV for less than 12 hours were included. NIV was associated with an improvement in the breathing pattern, better gas exchange, and less use of accessory muscles. The improvement in alveolar ventilation was translated as a partial reduction in $\mathrm{PCO} 2$ from 48 to $40 \mathrm{mmHg}$, and in a respiratory rate between 48 and 41.

A national retrospective cohort study evaluated children admitted to the ICU at the Cancer Hospital between June 1997 and May 2005. Included were 239 patients: 120 of them received NIV as the first technique for ventilation and 119 received conventional mechanical ventilation. Of the patients submitted to NIV, $25.8 \%$ required intubation. The groups were not paired, and the patients who received invasive mechanical ventilation were in more serious clinical condition. The values of arterial PCO2, hypoxemia, arterial $\mathrm{pH}$, and respiratory rate were no different between the two groups. The study results encourage the use of NIV as the first treatment in oncologic children with respiratory insufficiency, and without hemodynamic instability ${ }^{(19)}$.

Piastra et al. ${ }^{(22)}$ developed a prospective cohort study with 23 immunocompromised patients with ARDS admitted to the ICU of a university hospital and treated with NIV. There was no difference in the scores of severity between the NIV responders and non-responders. The improvement in the $\mathrm{PaO} 2 /$ $\mathrm{FiO} 2$ ratio was significant and precocious. Of the 23 patients, 13 were able to avoid intubation and were discharged from the ICU. Ten required intubation, and of these, two survived and eight died (two due to refractory hypoxemia, three due to septic shock, and three due to multiple organ failure). The mortality of non-responders to NIV was high both in the ICU and in the hospital, in general. ICU stay was shorted for those responsive to NIV, who also showed an improvement in heart and respiratory rates at the end of the treatment. It was concluded that NIV is well tolerated and feasible in children immunocompromised with ARDS, but a randomized controlled study is necessary to confirm the efficacy of this method.

\section{DISCUSSION}

The clinical evaluation of the benefits of NIV was performed by means of a randomized clinical trial with the general pediatric population ${ }^{(17)}$ and a trial in the subpopulation with asthma ${ }^{(10)}$. Such studies were not completely appropriate since they did not compare NIV with the invasive treatment, but with conventional treatment.

The other studies included in this review showed clinical improvement in children and adolescents treated with NIV. With ventilatory support provided via masks, the patients showed reduced respiratory discomfort, in addition to improved oxygenation and ventilation, assessed by arterial gasometry or by noninvasive monitoring methods, such as pulse oximetry.

Controlled studies in adults demonstrated similar results: reduction in respiratory rate, reduction in respiratory discomfort, and improvement in oxygenation ${ }^{(23,24)}$.

The studies carried out by Essouri et al. ${ }^{(16,18)}$ and Ottonello et al. ${ }^{(20)}$ allow rating and recommendation of use of NIV at the B-II level.

NIV proved particularly feasible in oncologic patients ${ }^{(19,22)}$. 


\section{CONCLUSION}

There is currently scientific evidence to recommend the routine use of NIV, withaB-IIdegree of recommendation, due to the reduced number of controlled and randomized studies. The articles published to date suggest beneficial physiological effects. New randomized studies with larger numbers of cases to better define the role of NIV in treating respiratory insufficiency in the pediatric population are welcome.

\section{REFERENCES}

1. Schettino GP, Reis MA, Galas F, Park M, Franca S, Okamoto V. [Mechanical ventilation noninvasive with positive pressure]. J Bras Pneumol. 2007:33 Suppl 2S:S92-105.

2. Ellis ER, McCauley VB, Mellis C, Sullivan CE. Treatment of alveolar hypoventilation in a six-year-old girl with intermittent positive pressure ventilation through a nose mask. Am Rev Respir Dis. 1987;136(1):188-91.

3. Guyatt GH, Oxman AD, Vist GE, Kunz R, Falck-Ytter Y, Alonso-Coello P, Schünemann HJ; GRADE Working Group. GRADE: an emerging consensus on rating quality of evidence and strength of recommendations. BMJ. 2008;336(7650):924-6.

4. Akingbola OA, Servant GM, Custer JR, Palmisano JM. Noninvasive bi-level positive pressure ventilation: management of two pediatric patients. Resp Care. 1993;38:1092-8.

5. Fortenberry JD, Del Toro J, Jefferson LS, Evey L, Haase D. Management of pediatric acute hypoxemic respiratory insufficiency with bi-level positive pressure (BiPAP) nasal mask ventilation. Chest. 1995;108(4):1059-64.

6. Padman R, Lawless ST, Kettrick RG. Noninvasive ventilation via bi-level positive airway pressure support in pediatric practice. Crit Care Med. 1998;26(1): 169-73.

7. Sprague K, Graff G, Tobias DJ. Noninvasive ventilation in respiratory failure due to cystic fibrosis. South Med J. 2000;93(10):954-61.

8. Akingbola OA, Simakajornboon N, Hadley Jr EF, Hopkins RL. Noninvasive positive-pressure ventilation in pediatric status asthmaticus. Pediatr Crit Care Med. 2002;3(2):181-4.

9. Shah PS, Ohlsson A, Shah JP. Continuous negative extrathoracic pressure or continuous positive airway pressure for acute hypoxemic respiratory failure in children. Cochrane Database Syst Rev. 2003(3):CD003699.

10. Thill PJ, McGuire JK, Baden HP, Green TP, Checchia PA. Noninvasive positivepressure ventilation in children with lower airway obstruction. Pediatr Crit Care Med. 2004;5(4):337-42.

11. Piastra M, Antonelli M, Chiaretti A, Polidori G, Polidori L, Conti G. Treatment of acute respiratory failure by helmet-delivered noninvasive pressure support ventilation in children with acute leukemia: a pilot study. Intensive Care Med. 2004;30(3):472-6.

12. Villanueva AME, Los Arcos Solas M, Galán CR, Torre AC, Cuervo SM, et al. Aplicación de ventilación no invasiva em una unidad de cuidados intensivos pediátricos. An Pediatr. 2005;62(1):13-9.

13. Chin K, Uemoto S, Takahashi K, Egawa $H$, Kasahara M, Fujimoto $Y$, et al. Noninvasive ventilation for pediatric patients including those under 1-year-old undergoing liver transplantation. Liver Transpl. 2005;11(2): 188-95.

14. Prado F, Godoy MA, Godoy M, Boza ML. [Pediatric noninvasive ventilation for acute respiratory failure in an Intermediate Care Unit]. Rev Med Chil. 2005; 133(5):525-33.

15. Carroll CL, Schramm CM. Noninvasive positive pressure ventilation for the treatment of status asthmaticus in children. Ann Allergy Asthma Immunol. 2006;96(3):454-9.

16. Essouri $S$, Chevret L, Durand P, Haas V, Fauroux B, Devictor D. Noninvasive positive pressure ventilation: five years of experience in a pediatric intensive care unit. Pediatr Crit Care Med. 2006;7(4):329-34.

17. Yañez LJ, Yunge M, Emilfork M, Lapadula M, Alcántara A, Fernández C, et al. A prospective, randomized, controlled trial of noninvasive ventilation in pediatric acute respiratory failure. Pediatr Crit Care Med. 2008;9(5): 484-9.

18. Essouri S, Durand P, Chevret L, Haas V, Perot C, Clement A, et al. Physiological effects of noninvasive positive ventilation during acute moderate hypercapnic respiratory insufficiency in children. Intensive Care Med. 2008;34(12): 2248-55.

19. Pancera CF, Hayashi M, Fregnani JH, Negri EM, Deheinzelin D, de Camargo B. Noninvasive ventilation in immunocompromised pediatric patients: eight years of experience in a pediatric oncology intensive care unit. J Pediatr Hematol Oncol. 2008;30(7):533-8.

20. Ottonello G, Villa G, Doglio L, Pedemonte M, Diana MC, Casciaro R, et al. Noninvasive ventilation with positive airway pressure in paediatric intensive care. Minerva Pediatr. 2007;59(2):85-9.

21. Codazzi D, Nacoti M, Passoni M, Bonanomi E, Sperti LR, Fumagalli R. Continuous positive airway pressure with modified helmet for treatment of hypoxemic acute respiratory failure in infants and a preschool population: a feasibility study. Pediatr Crit Care Med. 2006;7(4):455-60.

22. Piastra $M$, De Luca D, Pietrini D, Pulitanò $S$, DArrigo $S$, Mancino $A$, et al. Noninvasive pressure-support ventilation in immunocompromised children with ARDS: a feasibility study. Intensive Care Med. 2009;35(8):1420-7.

23. Soroksky A, Stav D, Shpirer I. A pilot prospective, randomized, placebocontrolled trial of bi-level positive airway pressure in acute asthmatic attack. Chest. 2003;123(4):1018-25.

24. Park M, Sangean MC, Volpe Mde S, et al. Randomized, prospective trial of oxygen, continuous positive airway pressure, and bi-level positive airway pressure by face mask in acute cardiogenic pulmonary edema. Crit Care Med. 2004;32(12):2407-15 